\title{
Reviewing interventions to enhance comfort and productivity of workers in Enterprises
}

\author{
Ekta Melkani, Kiran Singh and Manju Mehta
}

Received: 09.10.2020; Accepted: 20.11.2020

See end of the paper for authors' affiliations Ekta Melkani Department of Family Resource Management, I.C. College of Home Sceince, C.C.S. Haryana Agricultural University, Hisar (Haryana) India

Email : ektamelkani@gmail.com
ABSTRACT : The following study deals with the detailed reviews regarding the interventions that have been done globally in the sector of entrepreneurial interventions in aspect of work simplification. Various standards hence can be considered while referring to different designs for enterprises, especially small scale enterprises. The studies have revealed the musculoskeletal disorders from manual material handling $(\mathrm{MMH})$ works often involving strains and sprains to the lower back, shoulders, and upper limbs. The ergonomic interventions are found to give comfort to the workers in various postures. It is concluded that the design of the system must be incorporating to the worker, equipment, and environment as a whole.

KEY WORDS: Reviewing interventions, Enhance comfort, Productivity, Workers in Enterprises

- HOW TO CITE THIS PAPER : Melkani, Ekta, Singh, Kiran and Mehta, Manju (2020). Reviewing interventions to enhance comfort and productivity of workers in Enterprises. Asian J. Home Sci., 15 (2) : 419-423, DOI: 10.15740/HAS/AJHS/15.2/419-423. Copyright@ 2020: Hind Agri-Horticultural Society. 